\title{
Aerosol particles laden with COVID-19 travel over 30m distance
}

\author{
B. Gorbunov \\ Ancon Technologies Ltd, CIC, Univercity Rd., Canterbury, Kent CT2 7FG, UK; Ancon \\ Medical Inc., Bloomington, Minneapolis, Minnesota, USA
}

\begin{abstract}
Effects of the convection flow, atmospheric diffusivity and humidity on evolution and travel distances of exhaled aerosol clouds by an infected person are considered. The aim of this work is to evaluate the importance of aerosol transmission routes and the effectiveness of the 2-metre separation distance policy. A potential impact of use of face masks on the infection transmission rate, and an opportunity to reduce infection in hospitals, care homes and other public spaces by appropriate monitoring and filtering of air are also considered. The results obtained demonstrate that aerosol particles generated by coughing and sneezing can travel over $30 \mathrm{~m}$. Modelling of the evolution of aerosol clouds generated by coughing and sneezing enables us to evaluate the deposition dose of aerosol particles in healthy individuals. For example, a person in a public place (e.g. supermarket or car park) can accumulate in the respiratory system up to 200 virus copies in 2 min time by breathing in virus laden aerosols. Wearing face mask considerably reduces the deposited load down to 2 virus copies per $2 \mathrm{~min}$. The modelling also suggests that it should be possible to measure Covid-19 within aerosol particles in hospitals and public places, e.g. care homes and supermarkets.
\end{abstract}

\section{Introduction}

Understanding transmission of Covid-19 infection is one of the key issues the scientific community faces. Policymakers need urgent advices on strategic measures in combating the spread of the respiratory virus that causes Covid-19. Understanding the main virus transmission routes is vital for policy development to curb spread Covid-19 infection. The US Centres for Disease Control and Prevention recommends a 6-foot (2-m) separation distance. However, this exclusion distance is based on estimates of the range that have not considered convection flow and atmospheric diffusivity that affect dispersion of exhaled aerosol clouds considerably. Recent works on Covid-19 has shown that sneezes and coughs not only consist of mucosalivary droplets that quickly follow down by shortrange deposition trajectories but, importantly, are primarily made of a multiphase turbulent gas (a puff) cloud that entrains ambient air and carries aerosol particles, Bourouiba (2020). Pathogen-bearing particles within the air cloud coming out of the respiratory system are propelled as far as 27 feet $(8 \mathrm{~m})$, Bourouiba, et al., (2014). In a moist and warm atmosphere, the aerosol cloud particle evaporation is slower than occurs with isolated droplets. Under these conditions, the lifetime of a particle could be considerably extended by a factor of up to 1000, from a fraction of a second to minutes. Therefore, aerosols laden with viruses potentially may stay suspended in air long enough to travel for considerable distances. 
The initial stage of an airborne viral disease transmission is caused by virus laden droplets that are generated mainly by coughing, sneezing, or talking. This creates a population of airborne particles in the vicinity of a host. There is an ambiguity about terminology used for these particles: in some publications they described as droplets, but in others as aerosol particles, Bourouiba (2020). An added complexity is that the size of airborne particles is changing due to the air-particles mass transfer and the coagulation. Moreover, airborne particles exposed to a low humidity are described as nuclei implying that there is no water left in them, e.g. Yang et al. (2007). According to the chemical equilibrium concept the amount of water in a complex object as a particle generated by coughing is governed by equality of the chemical potential of water in the particle and in the air. In the air where $\mathrm{Rh}$ is often $45 \%$ to $70 \%$ moist particles generated by hosts are never dry, Pruppacher and Klett (1997). Here to avoid an ambiguity, airborne particles generated by infected persons are described as aerosol particles or aerosols assuming that these include other terms (droplets, and nuclei).

There are two major routes how infection can be transmitted from a host to another person: first, viruses are directly transmitted through the air by aerosol particles that are inhaled into the oronasopharynx and distally into the trachea and lung and second, an indirect transmission when viruses are transferred by contact with a contaminated intermediate object (fomite), Pica and Bouvier (2012). Other modes of transmission are not considered here as for example, contact transmission by contaminated hands (direct and indirect) or by kisses because they do not play an important role or do not pose a challenge in mitigation of the virus spread. Morawska (2006) confirmed that respiratory infectious diseases can be spread by airborne transmission. Airborne routes seemed to be more important in SARS coronavirus spread according to a review by Pica and Bouvier (2012). Hui (2010) also found that SARS may be transmitted through the airborne route as well. Rosa et al. (2013) found that viral infections can be acquired through aerosol routes indoors as well. Recently, Howard et al. (2020) have reported that a primary route of transmission of Covid-19 is likely via aerosol particles that are known to be transmissible from presymptomatic and asymptomatic individuals. Setti et al. (2020a) have also hypothesized the possibility that Covid-19 virus could be present on particulate matter during the spreading of the infection. The presence of Covid-19 virus on particulate matter in Northern Italy have been confirmed by Setti et al. (2020b).

It is rather difficult to dismiss the aerosol route of Covid-19 transmission from mitigation policy given a vast body of evidence indicating a potential possibility of this. Individual face masks undoubtedly can capture some aerosol particles laden with viruses. Nevertheless, there is a controversy about efficiency of using personal protective masks in curbing spread of viral infections. For example, Leung et al. (2020) reported that face masks significantly reduced detection of influenza virus RNA in aerosol particles. These results indicate that face masks could prevent transmission of human coronaviruses and influenza viruses from symptomatic individuals. On the other hand, Seongman et al. (2020) reported that both surgical and cotton masks seem to be ineffective in preventing the dissemination of SARS-CoV-2 from the coughs of patients with Covid-19 to the environment and external mask surface. However, authors surprisingly found greater contamination on the outer than the inner mask surfaces. This finding is difficult to explain without possibility of viral contamination of unknown origin. An investigation of effects of contaminations on the mask efficiency tests needs to be carried out.

van Doremalen et al. (2020) evaluated the stability of SARS-CoV-2 and SARS-CoV-1 in aerosols and on various surfaces and estimated their decay rates. SARS-CoV-2 remained viable in aerosols throughout the duration of the experiment ( 3 hours). Their results indicate that aerosol transmission of SARS-CoV-2 (Covid-19) is plausible, since the virus can remain viable 
and infectious in aerosols for hours and on surfaces up to days. On the contrary, Xiao et al. (2020) stated that although mechanistic studies support the potential effect of hand hygiene or face masks, evidence from some trials of these measures did not support a substantial effect on transmission of laboratory-confirmed influenza. They also found limited evidence on the effectiveness of improved hygiene and environmental cleaning.

A more detailed understanding of how airborne Covid-19 viruses spread can have broad public health implications. A variety of meteorological factors have been associated with rates of virus infection as well as transmission between individuals. As presented in review by Pica and Bouvier (2012), precipitation, humidity, temperature, and airflow can be determinants of virus infection and transmission. However, despite robust investigation of the effects of these environmental factors, inconsistencies and uncertainties in the data remain. Discrepancies in collected data suggest that more research is necessary to determine with increased certainty the role that environmental factors play in the transmission of viral pathogens exhaled by infected individuals.

Citing concern about asymptomatic and pre-symptomatic spread of Covid-19, the CDC recently recommended that all Americans should wear cloth masks in public. However, this is justifiable only if there are enough aerosol particles in the air loaded with copies of Covid-19 viruses and these particles travel over considerable distances.

In this paper, effects of the convection flow, atmospheric diffusivity, humidity and other relevant atmospheric factors on evolution of exhaled aerosol clouds, aerosol travel distances and transmission of infection are studied. The aim of this work is to evaluate the importance of aerosol transmission routes for Covid-19 and the effectiveness of the 2-metre distancing policy. The results obtained are employed to assess the importance of wearing face masks in reduction of the infection transmission rate. The exposure levels of the general population to Covid-19 virus via aerosol transmission route and deposited doses are calculated.

\section{Modelling of Covid-19 spread via the air}

The aerosol transformation processes relevant to dispersion of Covid-19 in the air were studied using 2D and 3D aerosol dynamics models using Comsol v5.5 finite element software, comprising urban atmospheric dispersion of trace species, gravitational settling and fluid dynamics. This model can easily be implemented to both Gaussian and Eulerian aerosol dispersion versions. Aerosol processes considered in this study were (i) the coagulation of particles, (ii) the condensation and evaporation of water form droplets, and (iii) dry deposition Karl, et al. (2016). The lung deposition model was based on ICRP (1994) with lung deposition efficiency from Gorbunov et al. (2004) and Ruzer, et al. (2005).

To evaluate the atmospheric dispersion of Covid-19 laden aerosol particles from the emission point, the Gaussian model was used, with simplified integrated turbulent diffusion coefficients. The urban microenvironments can be divided in three major groups: open mainly unobstructed spaces (supermarket parking, open space parks, etc.), street canyons and indoors rooms as well as offices. Here mainly open space modelling results are presented. Relatively simple geometry of an open space was studied. Dry deposition of particles was found to be negligible for dispersion of aerosol clouds with particles below $10 \mu \mathrm{m}$ in aerodynamic diameter and was omitted for these sizes, e.g. Baron and Willeke (2001). 
Atmospheric diffusivity and aerosol evolution

Dispersion of aerosol particles in the atmosphere is mainly influenced by the convection and turbulent diffusion. Atmospheric turbulence is intermittent in space and time. The diffusivity of such a patchy turbulence as atmospheric is mainly related to statistical parameters describing the morphology of turbulent events: filling factor, lifetime and height of the patches, etc., Wilson (2004). A statistical description of the turbulent characteristics is employed in order to evaluate the impact of small-scale turbulence on transport of aerosols. In-situ measurements of atmospheric diffusivity coefficients range from 0.2 to $0.8 \mathrm{~m} 2 / \mathrm{s}$, Alisse and Sidi (2000). There are many uncertainties with the atmospheric turbulence, for example Kennedy and Shapiro (1980) reported greater values and variations in the atmospheric diffusivity from circa 1 to 100 $\mathrm{m} 2 / \mathrm{s}$. In a boundary layer the atmospheric diffusion coefficient is in the range from 0.1 to 160 $\mathrm{m} 2 / \mathrm{s}$ depending on the stability of the atmosphere, the urban geometry and traffic, Hanna et al. (1982). In street canyons the atmospheric diffusion coefficient is likely to be in the range from 0.1 to $10 \mathrm{~m} 2 / \mathrm{s}$, ibid.

\section{Size of droplets generated by coughing and sneezing}

Aerosol is an unstable ensemble of airborne particles of different sizes and concentrations that is constantly changes due to external velocity field, gravitational settling, coagulation, diffusion and mass exchange with the gas medium surrounding the particles. Behaviour of aerosols is strongly influenced by the size of particles, Baron and Willeke (2001). Sneezing and coughing generate clouds of largely liquid aerosol particles in the air mainly in the size range from 1 to $100 \mu \mathrm{m}$, Han, et al. (2013). The maximum velocity of the exhaled airflow of a sneeze is around $30-100 \mathrm{~m} / \mathrm{s}$ Zhao, et al. (2005). This flow generates a complex mixture of particle spray containing particles of different sizes.

Particles of different sizes have significantly different dynamic characteristics. Relatively large droplets are deposited within 1 metre due to gravitational settling, Leder and Newman (2005). Smaller particles can travel long distances. Gustavo (2012) has detected high concentrations of submicron particles in cough aerosols. Yang, et al. (2007) measured concentration and size distributions of aerosol generated by coughing. Results showed that the total number concentration of aerosol particles was from $103 \mathrm{~cm}-3$ to $2 \cdot 10_{3} \mathrm{~cm}-3$. Average size range of the particles was $1-10 \mu \mathrm{m}$, and $50 \%$ of particles have diameter $>10 \mu \mathrm{m}$. The size range of particles generated by coughing and sneezing by infected humans is from $1 \mu \mathrm{m}$ to $100 \mu \mathrm{m}$. Here we assume that Covid-19 causes the same aerosol particle size distribution range from $1 \mu \mathrm{m}$ to $100 \mu \mathrm{m}$ as other airborne viral diseases. This assumption is the best hypothesis to date.

\section{Viral load}

The median viral load in posterior oropharyngeal saliva or other respiratory specimens at presentation was $5 \cdot 2 \log$ copies per ml. Maximal virus loading was found circa 108 copies $/ \mathrm{mL}$. Kai-Wang et al. (2020). The viral loads in throat swab and sputum samples peaked at around 5-6 days after symptom onset, ranging from around 103 to $7.11 \cdot 108$ copies per $\mathrm{mL}$ according to Evidence summary for COVID-19 viral load over course of infection, (2020). There is no evidence on the viral load in aerosol particles generated by an infected person. The data obtained from swabs are used here as proxy to evaluate number of virus copies in aerosol particles. In the absence of direct measurements, the assumption of equal viral loads in the posterior oropharyngeal saliva and in the aerosol particles is the best hypothesis at the moment. 
Two types of aerosol sources have been modelled: a steady-state source and time-dependent source. The latter is related to a single coughing or sneezing act, generating a cloud that evolves and moves with time. The first one is a simplification of a constant aerosol generation process as during talking.

\section{Results and discussions}

Steady-state aerosol source

First, an open space aerosol dispersion small-scale 2D steady-state model was developed and employed to evaluate the influence of the wind velocity on the possibility of transferring aerosol particles from the source to an uninfected person. In the model, aerosol particles of sizes close to sizes those observed in coughing, talking and sneezing experiments were considered. Concentration field of aerosol particles $\left(C_{X Y}\right)$ have been calculated in $\mathrm{X}-\mathrm{Y}$ space.

It was found that aerosol particles were carried out with the convection flow and spread from the source in all directions. An open space geometry modelled with wind speed $0.3 \mathrm{~m} / \mathrm{s}(0.66$ mph) shows that small particles travel considerable distances, greater than 10 meters, Fig. 1.

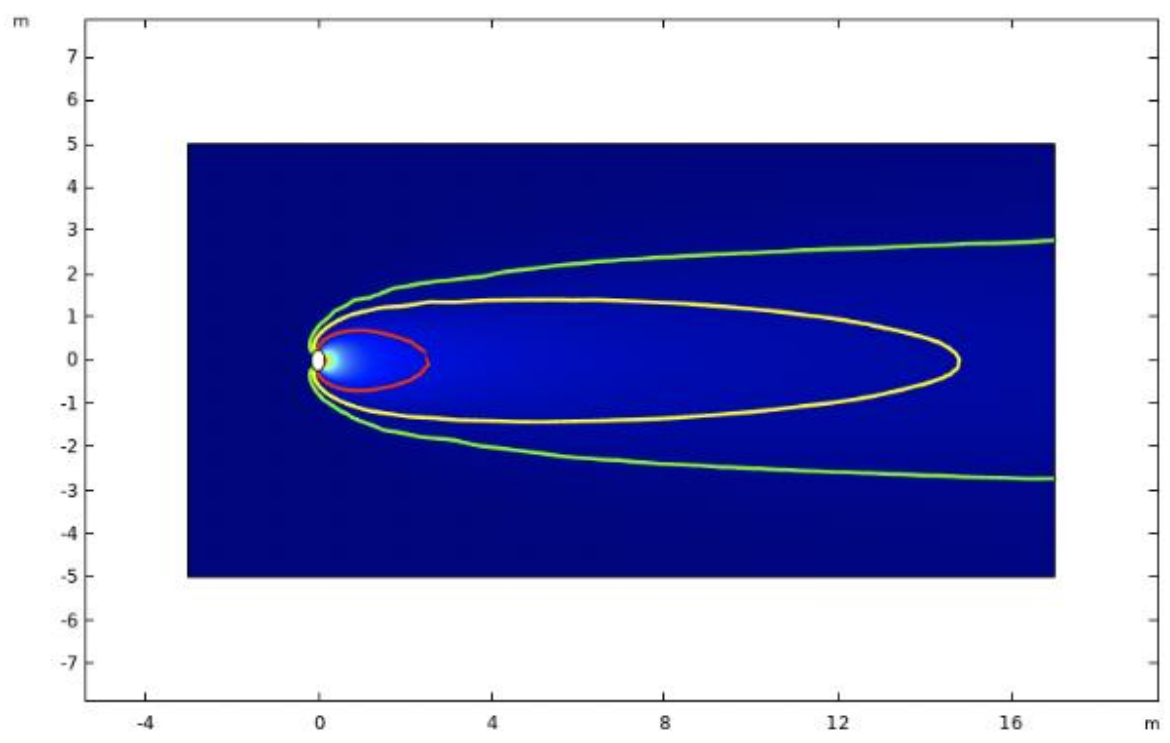

Figure 1. Contour plot of the concentration field of aerosol particles from a single source of Covid-19 forming an aerosol cloud plume in the area of $10 \mathrm{~m}$ x $20 \mathrm{~m}$. Velocity of air $-0.3 \mathrm{~m} / \mathrm{s}$ (0.66 mph), atmospheric diffusivity $-0.05 \mathrm{~m} 2 / \mathrm{s}$. Contour lines show the concentration of aerosol particles: $100 \mathrm{~cm}-3$ - read line, $40 \mathrm{~cm}-3$ - yellow line and $20 \mathrm{~cm}-3$ - green line.

An aerosol particle concentration field forms a narrow plume from the source directed downwind. If we assume that the concentration of particles near the source is $1,000 \mathrm{~cm}-3$ then the concentration shown with a red contour line $(C X Y=100 \mathrm{~cm}-3)$ reaches almost $3 \mathrm{~m}$ distance from the source. The concentration shown with yellow contour line $\left(C_{X Y}=40 \mathrm{~cm}-3\right)$ covers over 15-meter distance from the source of the aerosol particles. Interestingly the green contour line $(C X Y=20 \mathrm{~cm}-3)$ is considerably longer and it is spread far beyond 17 meters. The concentration field is highly asymmetric. The upwind area is completely clean from aerosol particles emitted 
from the source. Modelling demonstrates a strong influence of convection on the spread of aerosol particles along the $\mathrm{X}$-axis, but diffusivity is responsible for dispersion of particles along the $\mathrm{Y}$-axis.

On a quiet day, the average air wind speed at the height of 1.5 to 2 meters above the ground is $\sim 0.3 \mathrm{~m} / \mathrm{s}$. On a moderate day, with a higher wind speed, for example $1 \mathrm{~m} / \mathrm{s}$, an extend of each contour plot line is decreased. For example, the yellow contour line covers less than 9 meter length, Fig. 2 where in Fig. 1 it is 15 meters. This is explained by the faster movement of the aerosol and decrease in the concentration of particles due to a greater dilution of the aerosol. The area of each contour line zone at wind velocity $1 \mathrm{~m} / \mathrm{s}$ is roughly 3 times smaller than the area of the zone at $0.3 \mathrm{~m} / \mathrm{s}$. This effect is well known in air pollution research when higher wind speed episodes are associated with lower concentrations of aerosol particles. This decreases the area of the plume and therefore, chances that general public to be exposed to the virus laden aerosol particles. Therefore, in a windy day the viral infection transfer rate should be lower than in a quiet day.

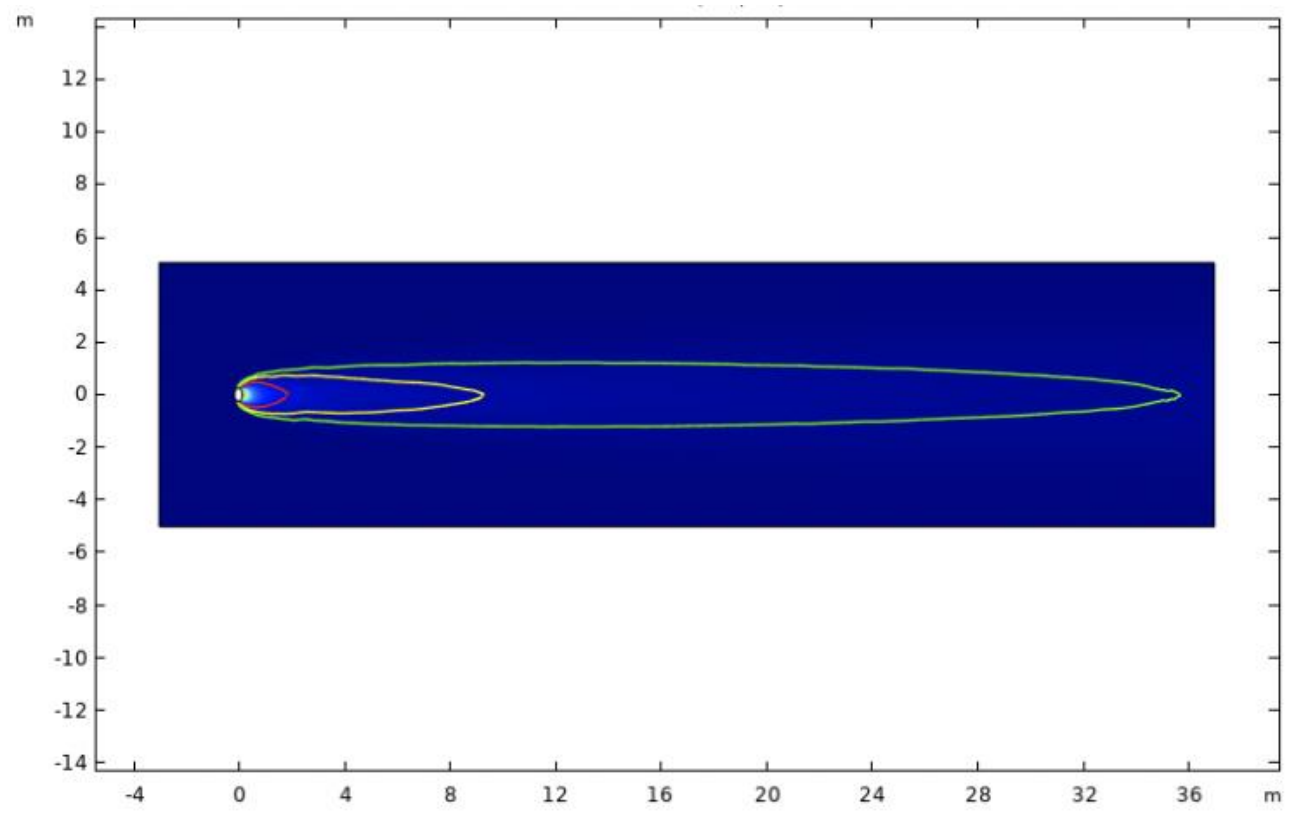

Figure 2. Contour plot of the concentration field of aerosol particles from a single source of Covid-19 forming an aerosol cloud plume in the area of $10 \mathrm{~m} \times 40 \mathrm{~m}$. Velocity of air $-1 \mathrm{~m} / \mathrm{s}$ $(2.2 \mathrm{mph})$, atmospheric diffusivity $-0.05 \mathrm{~m} 2 / \mathrm{s}$. Contour lines show the concentration of aerosol particles: $100 \mathrm{~cm}-3$ - read line, $40 \mathrm{~cm}-3$ - yellow line and $20 \mathrm{~cm}-3$ - green line. Extended version of the geometry in Fig. 1.

Interestingly the yellow contour line in Fig. 2 covers 36-meter distance. Thus, even on a moderate day aerosol particles spread over large distances.

Time-dependent modelling of evolution of a droplet cloud in an open space

Here we consider a case when a potential infection is spread via the aerosol route in an open space as a result of a single coughing or sneezing act. A supermarket parking $(10 \mathrm{~m} \mathrm{x} 20 \mathrm{~m})$ with a moderate wind speed in a dry weather is considered. In this case, a simple scenario of the infection spread is a single infected person is coming to the supermarket and walking across the parking area to the entrance. At some time whilst being in the car park the person generates 
an aerosol cloud containing small $(1 \mu \mathrm{m}<D p<10 \mu \mathrm{m})$ and larger $(D p>10 \mu \mathrm{m})$ aerosol particles by a single cough; where $D p$ is the aerodynamic diameter of a particle, Baron and Willeke (2001). The larger aerosol particles are quickly removed from the cloud due to sedimentation to the ground in the vicinity of the source, but the smaller particles may travel for longer distances (due to a lower terminal velocity) similar to distances shown in modelling of the steady-state aerosol source. These small particles within the aerosol cloud undergo constant transformations governed mainly by the atmospheric diffusion and convection caused by the 3D velocity field generated by the wind speed. The convection is also influenced by buoyancy, movement of people, machines and animals. This evolution of the cloud causes changes in the shape, location, concentration and size distributions of particles. In this modelling, all the driving forces of convection except for the wind velocity were integrated into an atmospheric diffusion coefficient. The main aim of this modelling was to estimate the range of the aerosol spread but not minute details of aerosol evolution on a meter-scale.

The initial size of the aerosol cloud generated by a single cough was assumed to be $0.5 \mathrm{~m} \times 1 \mathrm{~m}$ with concentration of particles $103 \mathrm{~cm}-3$. It might seem to be too large for a cloud generated by a human lung with volume of several litres. However, the cloud is not a uniform formation, but rather a result of highly turbulent mixture of the jet coming out of the lungs with the surrounding air. It is a patchy and non-uniform unstable formation that is similar but more violent than a smoking puff, e.g. see Bourouiba (2020).

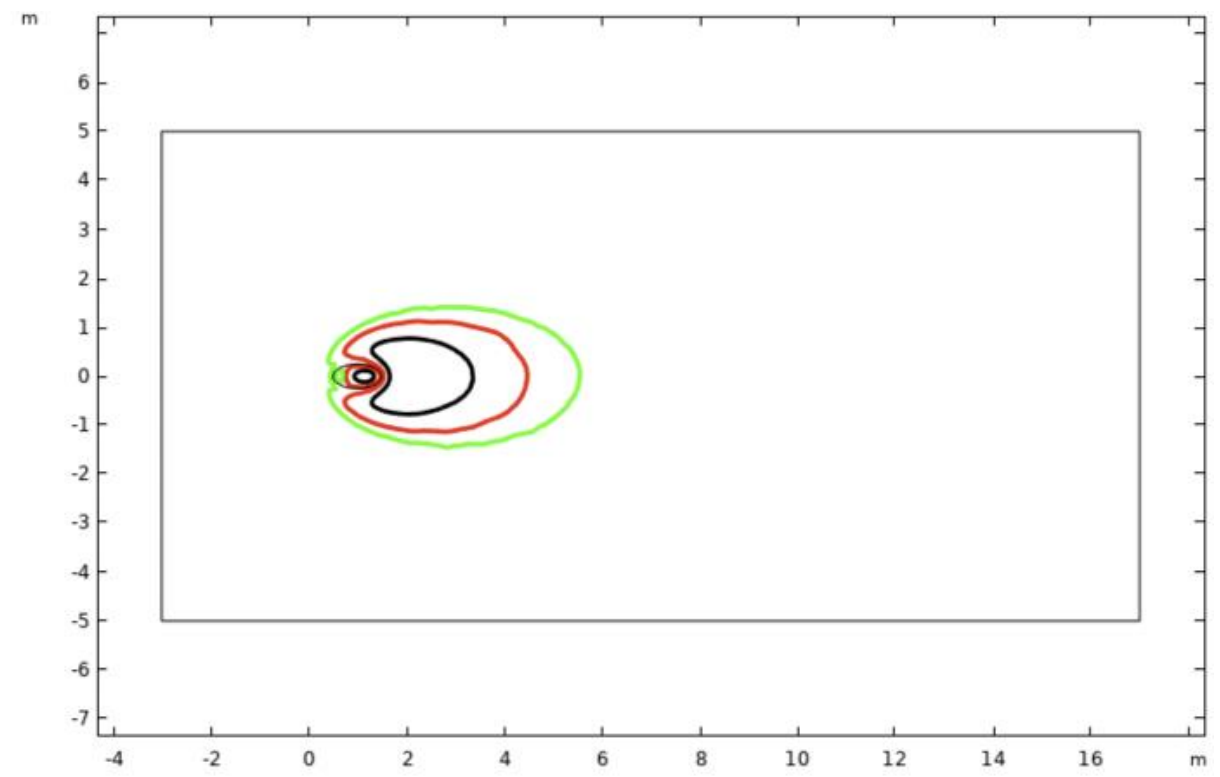

Figure 3a. A 2D XY cross-section of number concentration field of aerosol particles in the size range $1 \mu \mathrm{m}\langle D p<10 \mu \mathrm{m}$ at $\mathrm{Z}=1.7 \mathrm{~m}$ at the beginning of the aerosol cloud evolution, time $-6 \mathrm{~s}$. Wind speed $0.3 \mathrm{~m} / \mathrm{s} ; \mathrm{T}=20 \mathrm{\circ C}$; diffusivity $D f=0.03 \mathrm{~m} 2 / \mathrm{s}$. Contour lines are: $300 \mathrm{~cm}-3-$ black, $100 \mathrm{~cm}-3$ - read and $40 \mathrm{~cm}-3$ - green. Initial concentration in the aerosol cloud was $1,000 \mathrm{~cm}-3$ - thin black line ellipse, better can be seen in Fig. 3 b-e. The $\mathrm{Z}$ axis is perpendicular to the image.

After first 6 seconds the cloud has grown up to 6 metres, see aerosol particles concentration contour line $C_{X Y}=40 \mathrm{~cm}-3$ (green line) in Fig. 3a. In the centre of the cloud particle concentration is higher than $300 \mathrm{~cm}-3$ (black line). Then the cloud moved with the wind further along the $\mathrm{X}$-axis and become wider in X-Y plane, Fig. 3b-e. At the same time the particle 
Preprints (www.preprints.org)

NOT PEER-REVIEWED

Posted: 30 April 2020

doi:10.20944/preprints202004.0546.v1

concentration in the cloud is decreasing due to dispersion by atmospheric diffusion and by dilution. The black contour line has disappeared first (Fig.3c) and then the red line disappeared also (Fig. Bd). At $54 \mathrm{~s}$ even the area inside of the green contour line becomes smaller and the centre of it went up to 14 metre in distance from the source. Therefore, non-steady-state modelling confirms that aerosol particles generated by a cough can travel considerable distances from the source in excess of 10 metres.

The aerosol evolution data show a fast movement of the cloud defined by contour plot lines, Fig. 3. The contour plot indicates certain concentration levels. Between the levels shown in Fig. 3 the concentration field is formed by smooth functions that are influenced by space and time. See for example Fig. 4, where $C_{X, Y, Z, t}$ at $Y=0, Z=1.7 \mathrm{~m}$ shows smooth functions for the conditions as in Fig. Bb -Fig. Be.
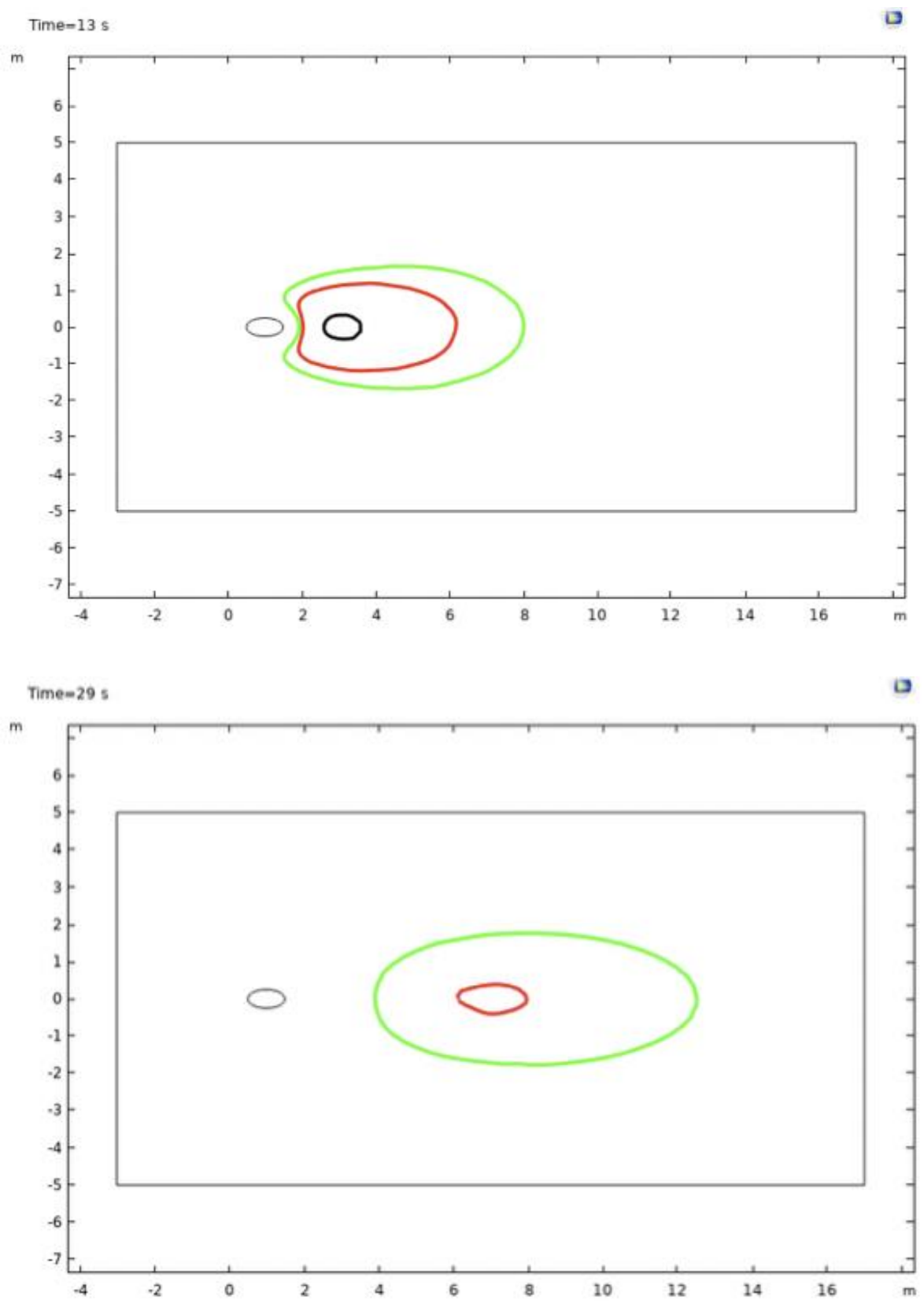

8 

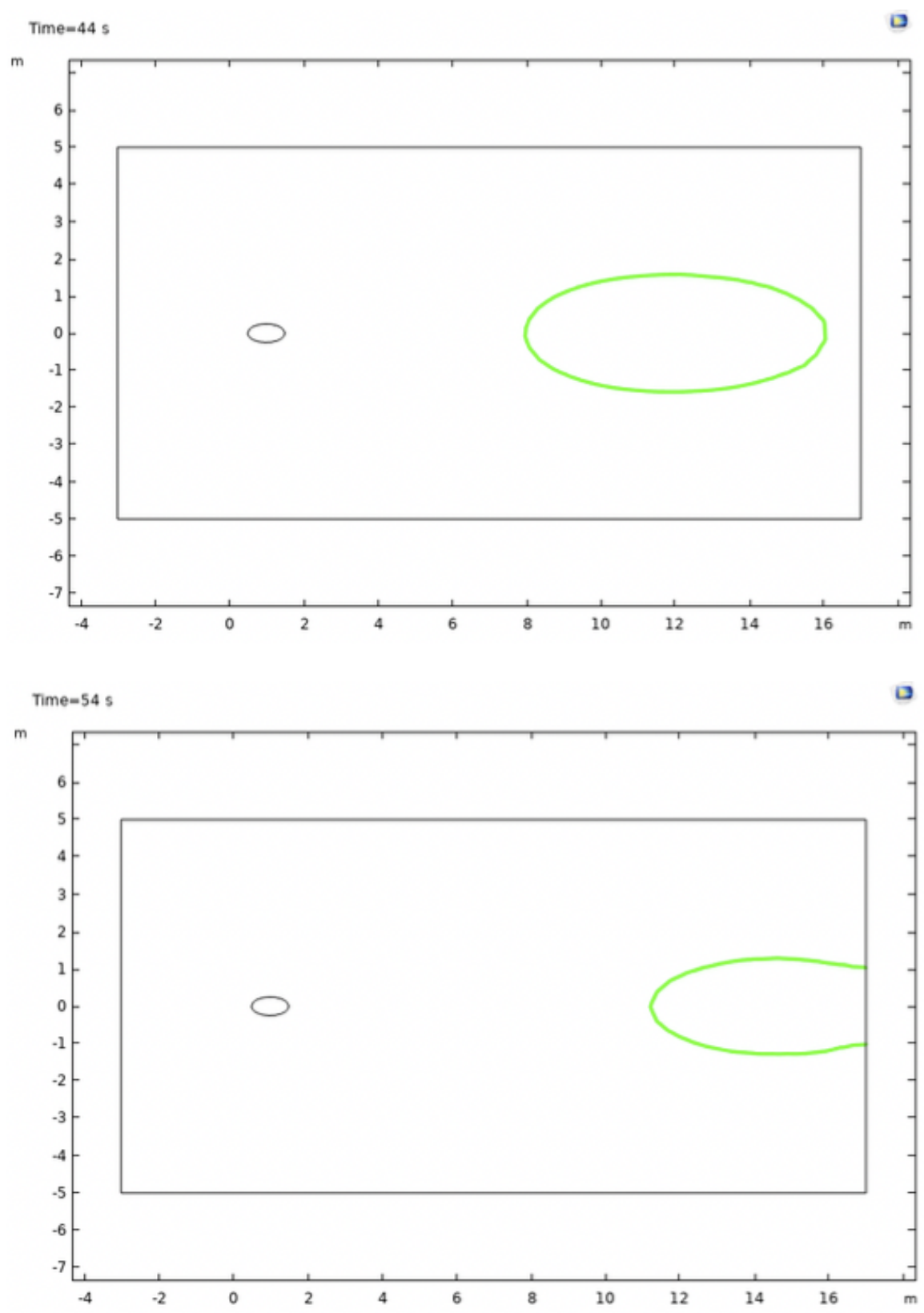

Figure $3 \mathrm{~b}-\mathrm{e}$. Contour plots were calculated at times: $\mathrm{b}$ (at the top) - $13 \mathrm{~s}$, c (second down) $29 \mathrm{~s}, \mathrm{~d}$ (third down) $-44 \mathrm{~s}$ and e (at the bottom) - 54 s. Other parameters as in Fig. 3a.

With time, individual clouds generated by different sources form a single aerosol particle concentration field that will travel considerable distances over an urban area and generating urban-scale viral pollution level. It is possible to speculate that individual source plumes ever spread and widen to form a background pollution level in the urban environment.

It is a generic aerosol modelling and we have not specified infection here, but the size distributions and concentrations of particles have been chosen to be close to these reported in the literature for Covid-19 or recent airborne viral infections close to Covid-19 (SARS, MERS). If Covid-19 laden aerosol particles behave similarly to aerosols described here, then the virus can be transferred over distances exceeding the currently recommended 2-metre safe zone considerably. 


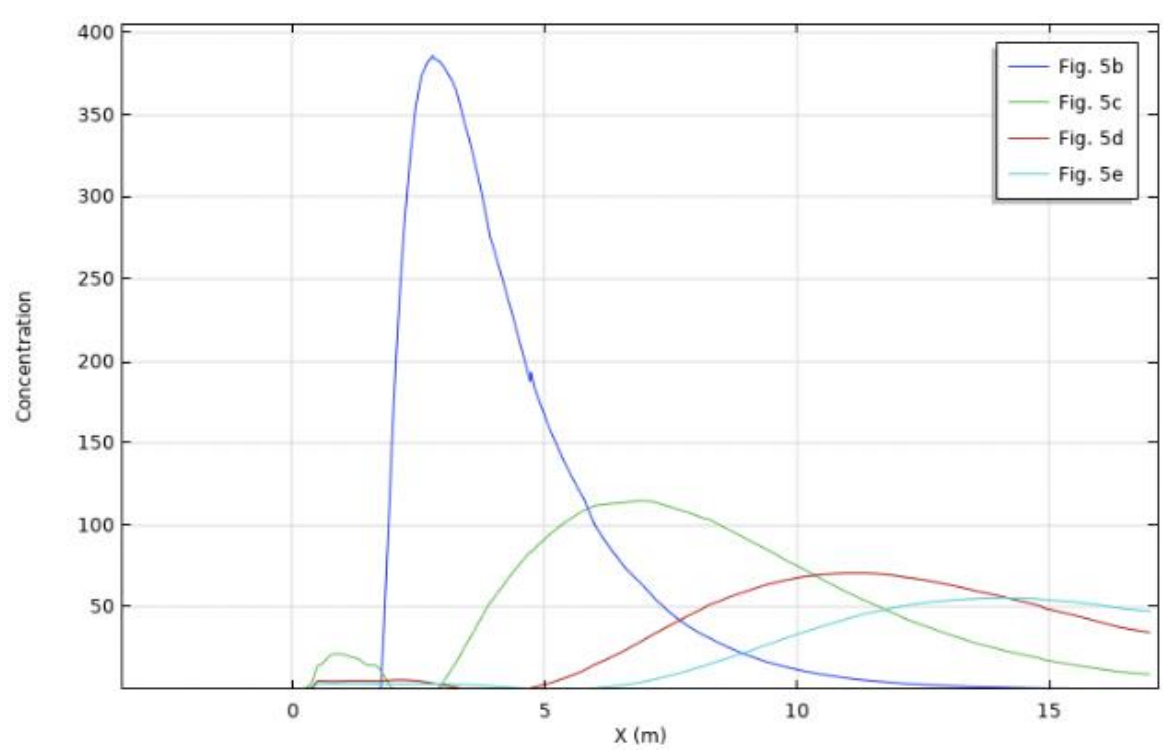

Figure 4. Concentration (in $\mathrm{cm}-3$ ) profile $C X, Y, Z, t$ at $\mathrm{Y}=0, \mathrm{Z}=1.7 \mathrm{~m}$ for the conditions shown in Fig. $3 b-$ Fig. $3 e$ vs. the $\mathrm{X}$-axis.

Travel distances of aerosol particles in a laminar flow

A case of a laminar flow was studied to evaluate effect of gravitation on the aerosol particle travel length. In this case, the turbulent diffusion is negligible or does not exist, therefore particles travel horizontally with the air mass and diverge towards ground due to the gravitational pull. It is a good illustration of the finding in the 2D and 3D numerical modelling. Average travel distances of aerosol particles before reaching the ground are good indicators for evaluation of the safe distances.

Average travel distances have been calculated for aerosol particles generated by infected individuals for $D p$ from $1 \mu \mathrm{m}$ to $100 \mu \mathrm{m}$ for a high humidity environment $(\mathrm{Rh}>80 \%)$. Evaporation of water from the particles in such an environment is negligible and therefore, after leaving the host sizes of particles remain the same and reach the ground quicker. Diffusivity and both dry and wet depositions have not been taken into account. The purpose of this is to evaluate the influence of wind speed on the minimal aerosol travel distances (that are not affected by other factors except for the earth gravity and the wind speed). At wind speeds from $0.3 \mathrm{~m} / \mathrm{s}$ to $3 \mathrm{~m} / \mathrm{s}$, travel distances are rapidly decreasing with increase in $D p$, Fig. 5 . Smaller particles with $D p=1 \mu \mathrm{m}$ travel in excess of 10,000 meters. Particles with $D p=10 \mu \mathrm{m}$ travel in excess of 100 meters. An increase in the wind speed increases travel distances. Aerosol particles in the range $1 \mu \mathrm{m}<D p<100 \mu \mathrm{m}$ for all considered wind speeds travel more than the 2 $\mathrm{m}$ "safe" recommended distance. Even the largest particles of $100 \mu \mathrm{m}$ at lowest velocity 0.3 $\mathrm{m} / \mathrm{s}$ in Fig. 5, travel $3.6 \mathrm{~m}$ from the source. It allows us to conclude that under normal weather conditions aerosol particles generated by an infected person travel over distances from meters to many kilometres in the air potentially spreading Covid-19 infection.

\section{Application to confined spaces}

The modelling in open spaces was adapted to confined spaces. For this the wind speed was replaced by the convection driven by buoyancy (e.g. caused by heating radiators and electronic devices), ventilation, movement of people and pets. These create a complex non-uniform and unstable 3D velocity field. In modelling, integrated diffusion coefficients were employed as in the modelling for open spaces. It was found that if an infective person generates an aerosol 
cloud in a room of $5 \mathrm{~m} \times 10 \mathrm{~m}$ by a single cough the cloud spread very quickly over the entire room in $\sim 100 \mathrm{~s}$. The difference between an open space and the confined space is the volume where the aerosol can be dispersed and the number of aerosol emission acts. It is known that an infected person generates aerosol particles during coughing, sneezing and talking. In a confined space these acts result in building up a high concentration of aerosol particles. Large particles $(10 \mu \mathrm{m}<D p<100 \mu \mathrm{m})$ eventually will be deposited onto the floor or plants, but smaller can dwell in the room for hours.

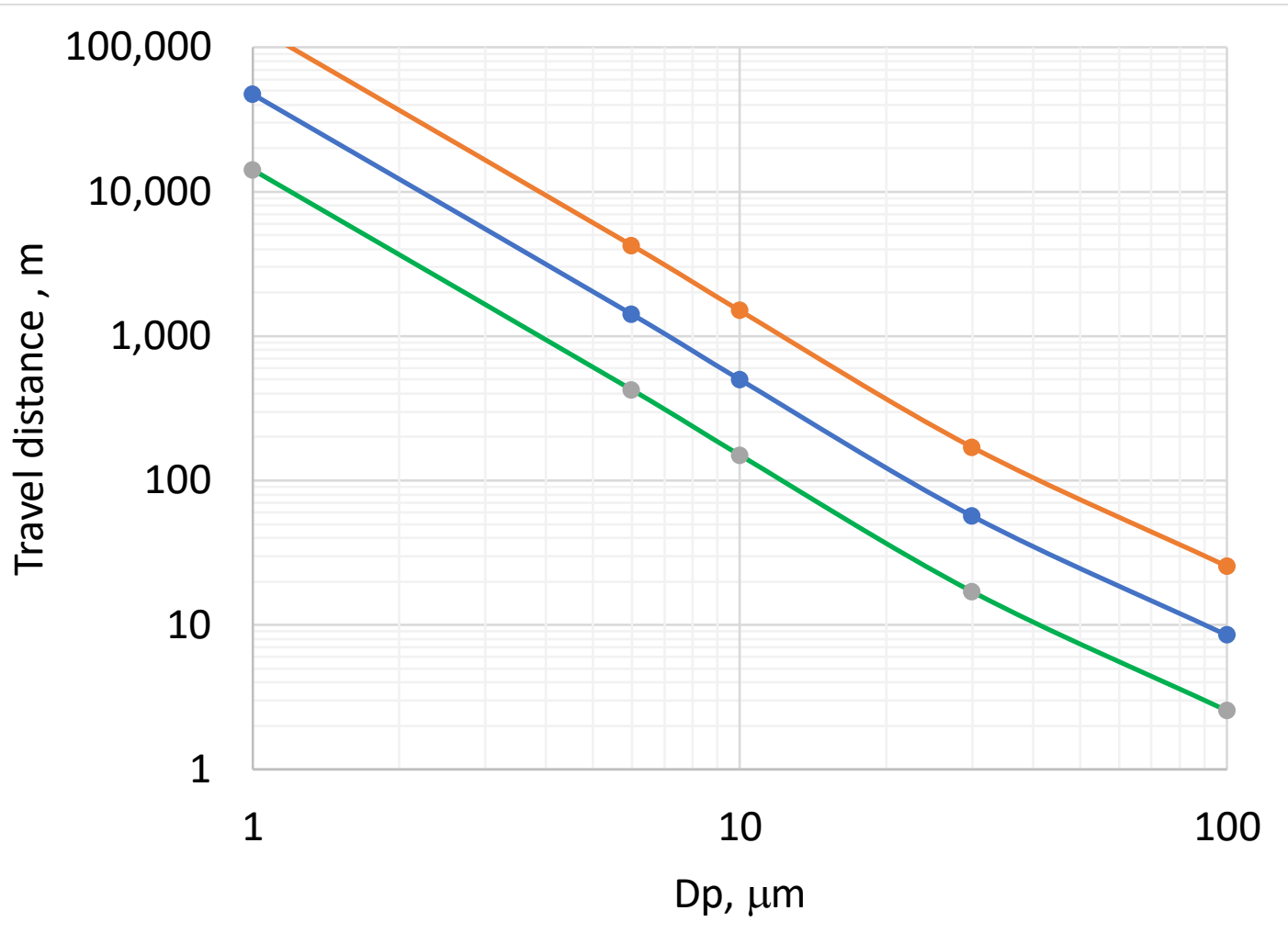

Figure 5. Average travel distances of aerosol particles in an open space vs. aerodynamic diameter calculated at wind speed: $0.3 \mathrm{~m} / \mathrm{s}$ (green line), $1 \mathrm{~m} / \mathrm{s}$ (blue line), $3 \mathrm{~m} / \mathrm{s}$ (orange line). $\mathrm{Rh}>80 \%$.

This generates a constant increase in the concentration of aerosol particles laden with viruses. Aerosol particles are trapped in the confined space. There are only two effective ways to control the aerosol concentration: ventilation and use of air purifiers. It should be considered beneficial to use air purifiers in houses and care homes where presence of infection is possible.

Number of Covid-19 copies deposited in a person exposed to the aerosol particles

This modelling indicates a potential possibility of the aerosol route for transmission of Covid19 infection. Here we are using the modelling results to evaluate the number of aerosol particles that can be transferred from a host to a healthy individual. To evaluate transfer of a viral infection, first an aerosol particle concentration field $C_{X, Y, Z, t}$ was calculated as described above and then an International Commission on Radiological Protection (ICRP) lung deposition model, e.g. from Hinds (1999), was applied to evaluate number of the aerosol particles deposited in the respiratory tract as it was described by Gorbunov et al. (2013) and Gorbunov et al. (2009). 


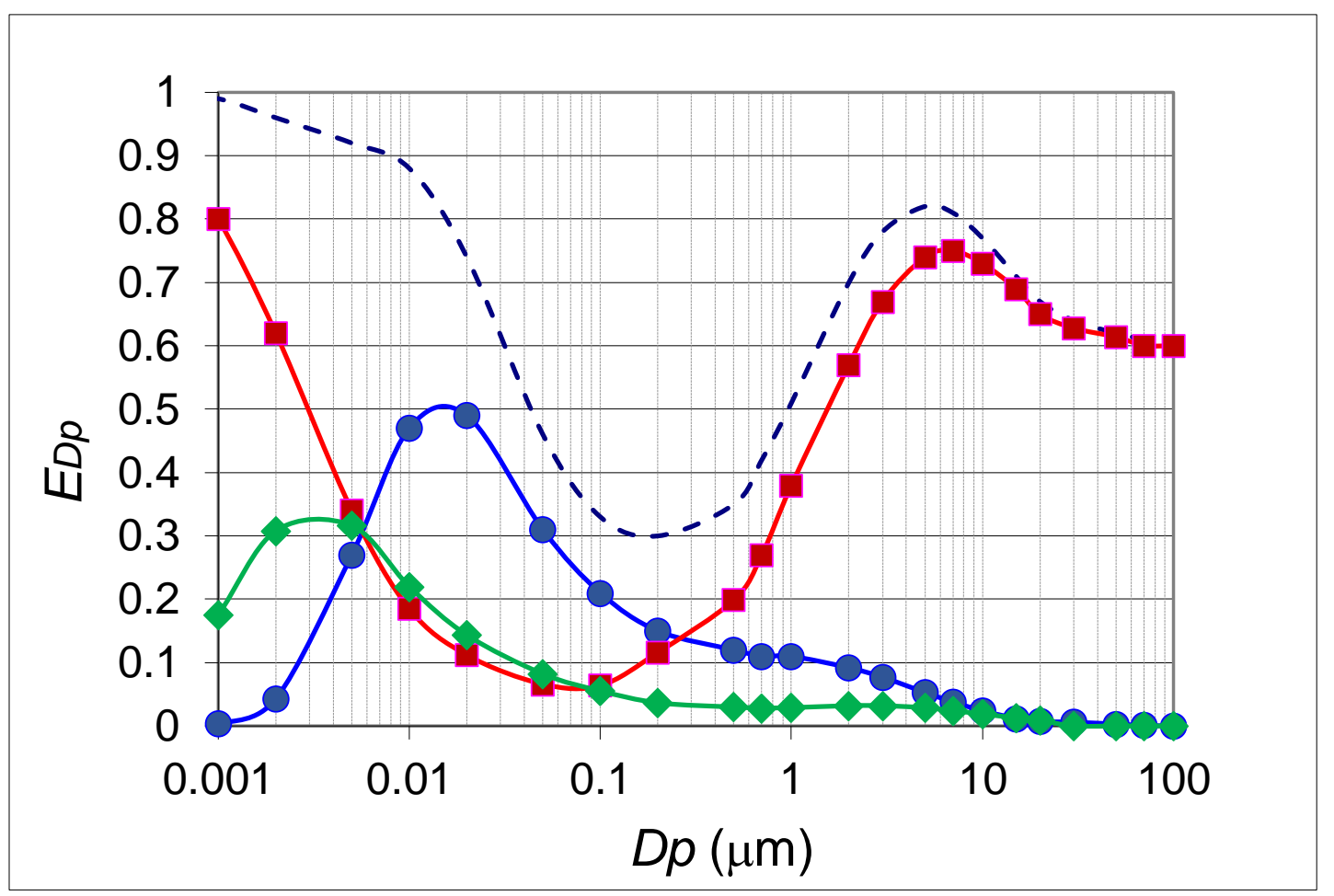

Figure 6. Aerosol particle deposition efficiency curves $\left(E_{D p}\right)$ vs. diameter of aerosol particles. The total deposition in the respiratory system shown with the dashed black curve and regional depositions are shown with coloured lines: the upper respiratory tract (red line), tracheobronchial region (green line) and alveolar region (blue line).

The total number of particles deposited in the respiratory system of a person who is at point $\{X, Y, Z, t\}$ after a single breath $\left(N_{p d}\right)$ can be found from:

$N_{p d}=\int_{D p=1 \mu}^{D p=100 \mu} C_{X, Y, Z, t, D p} \cdot E_{D p} d D p$

Here $E_{D p}$ is the deposition efficiency of aerosol particles in the respiratory system as function of the particle size, Fig. 6. The aerosol particle number size distribution has been included in expression (1) and indicated as variable $D p$ in $C_{X, Y, Z, t, D p}$. So in expression (1) $C_{X, Y, Z, t, D p}$ is a 5dimensional function of space, time and particle size. The initial size distribution of droplets was taken from Yang et al. (2007).

It is interesting that according to the ICRP deposition efficiency the particles relevant to Covid19 transmission $(1 \mu \mathrm{m}<D p<100 \mu \mathrm{m})$ are captured by the upper respiratory tract. Therefore, the face masks for Covid-19 should be designed to filter out particles in the range from $1 \mu \mathrm{m}$ to $100 \mu \mathrm{m}$. The current face mask industry standard does not include testing in this size range, Shu-An Lee et al. (2016).

The accumulated dose $\left(A D_{p d}\right)$ is the total virus copies number deposited in the respiratory tract after number of breathing cycles $n$. It should be noted that $n$ may or may not be constant. The average breath rate is $\sim 5$ cycles per minute. It is influenced by the physical activity, age and gender. 


$$
A D_{p d}=N p d \cdot n
$$

The number of breath cycles and the concentration of the aerosol particles defines the deposition dose of a person that is exposed to the aerosol. Initially, the deposition dose was calculated for monodisperse aerosol particles of different diameters and different concentrations and humidity of the air. The humidity in modelling was $\mathrm{Rh}=50 \%$ (low humidity) and $\mathrm{Rh}=80 \%$ (humidity of the exhaled air).

A typical concentration of $30 \mathrm{~cm}-3$ and $n=10$ show a steep function of $A D p d$ vs. $D p$, Fig. 7. After only 10 breathing cycles of $10 \mu \mathrm{m}$ particles, a person exposed to the typical concentration received a dose of 20 copies of viruses in a humid air and 600 copies - in the dry air. The increase of the dose in the dry air is caused by evaporation of water from larger particles, which have greater number of copies due to larger initial size of particles exhaled from the host. Here we assumed that the number of virus copies in a particle is equal to the volume of the particle by the virus load (3.105 cm-3). For particles of $20 \mu \mathrm{m}$, the deposition dose is 160 copies of viruses in a humid air and 4,000 copies - in the dry air.

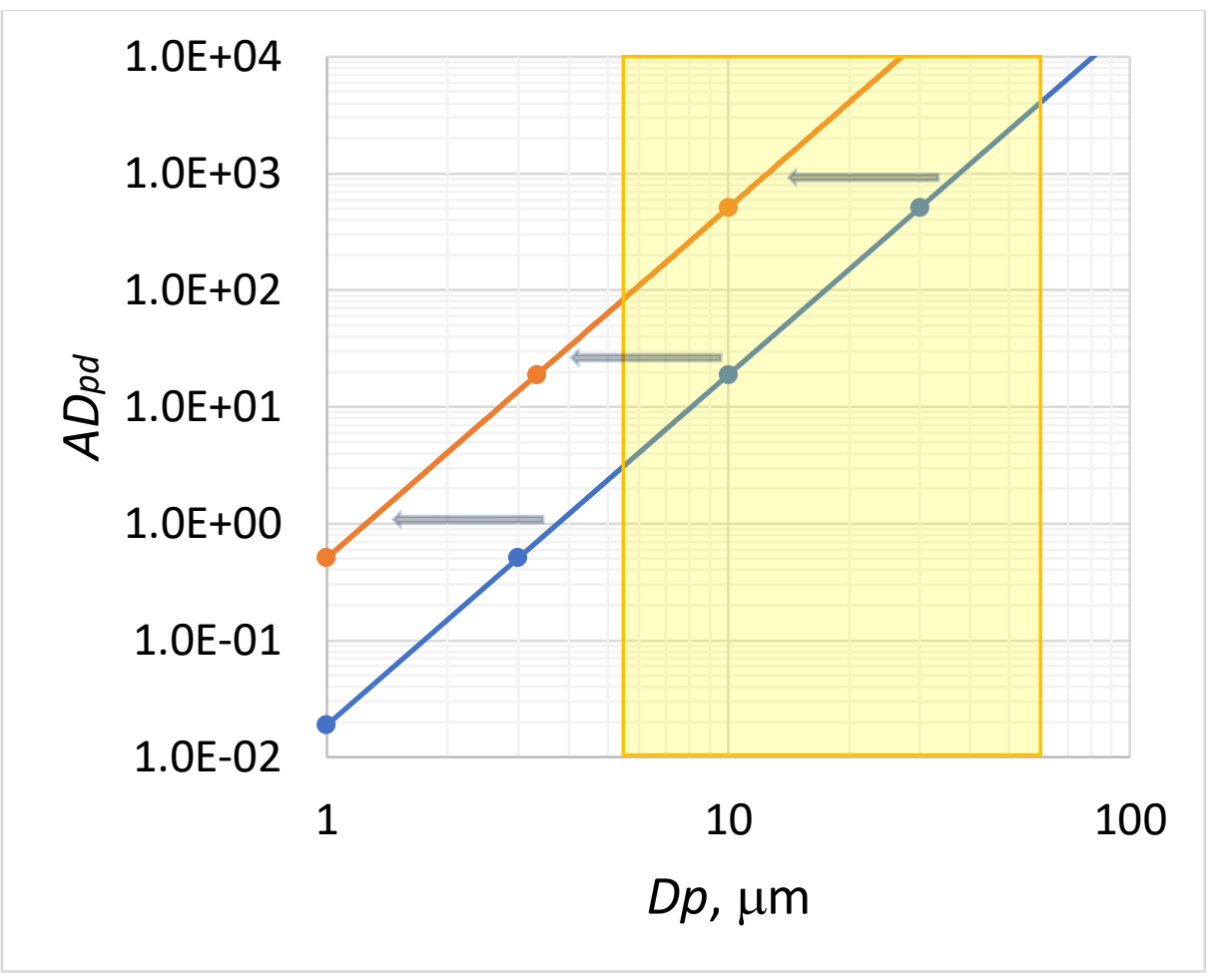

Figure 7. Number of virus copies deposited in the respiratory tract $\left(A D_{p d}\right)$ of a person exposed to a monodisperse aerosol of $30 \mathrm{~cm}^{-3}$ generated by an infected individual vs. aerodynamic particle diameter in a humid atmosphere (blue line) and in the dry air (orange line). The number of breathing cycles $n=10$. The light-yellow square shows the range of aerodynamic diameters of droplets that are most likely generated by Covid-19 patients and stays in the air.

There is no much information on the minimal deposited dose for the infection to be transferred from a host to a healthy person. There is no consensus on this number in the literature, however the dose of hundreds and thousands copies of Covid-19 supports the aerosol infection transmission route. This also justifies considering aerosol route seriously and informing policy 
makers and general public about possible ways of mitigating resk of exposure to the aerosol particles laden with viruses.

\section{Importance of protective face masks}

The results of modelling show that the aerosol route of the infection cannot be excluded, then the 2-metre distance is not safe and other means might be necessary to curb the infection spread. Importance of masks to reduce Covid-19 spread have been evaluated in the steady-state and time-dependent modelling of aerosol cloud evolution. The modelling demonstrates that in an open space or in a supermarket, a healthy person without face mask can get a deposition dose $A D_{p d}=200$ virus copies in $2 \mathrm{~min}$. If an infected person used a face mask than the $A D_{p d}$ reduced down to 20 copies according to Yang et al. (2007) who reported 10 times reduction in number of particles generated by coughing measured with and without face mask on the host.

An even greater effect on reducing the dose accumulated by providing uninfected individuals with face masks. Wearing a face mask with $95 \%$ of filtering efficiency reduces dose down to 10 copies of Covid-19. Wearing masks on both hosts and healthy individuals reduces the accumulated dose down to 2 copies per $2 \mathrm{~min}$. It is a possible solution to the problem of spreading airborne infection that cannot be ignored.

Results found in this work are supported by findings from other teams. A retrospective cohort study conducted after the SARS epidemic in Hong Kong in 2003 suggested that airborne spread may have played an important role in the transmission of that disease, Yu et al. (2014). Report of the WHO-China Joint Mission on Coronavirus Disease 2019 (COVID-19) World Health Organization, (2020) states that "Every citizen has to wear a mask in public." Citing concern about asymptomatic and pre-symptomatic spread of COVID-19, the CDC recommended that all Americans should wear cloth masks in public, CDC USA (2020).

It should be mentioned that the described aerosol transmission route is not the only one. The majority of aerosol emissions by coughing and sneezing are not in dynamic environments where many people do e.g. shopping, but in hospitals, care homes and in private homes. In enclosed environments with infected persons, aerosol concentrations can be built up because of the high frequency of coughing and stay at high levels. From homes some aerosols may escape outside for instance into "street canyons". It is difficult to guess the fraction of escaped aerosol particles. From the air pollution monitoring we know that the indoors particle concentration is a half of the concentration outside, Baron and Willeke (2001). However, this does not mean that the concentration of escaped aerosol particles would be a half of the concentration inside houses. To say nothing about uncertainties with the concentration inside houses harbouring an infected person.

The spread of infection through the air suggests that some steps should be taken urgently to reduce transmission of the infection. For example, installing appropriate filter systems to remove the virus from the air will reduce the virus presence and therefore, transmission rate in care homes and private homes. A number of air purifying devises are available on the market. Modelling suggests using these devices to reduce airborne viral infection transmission rate in confined spaces. Modelling also suggests a number of optimal ways to deploy air filtering systems in hospitals, residential care homes and public places that will improve the air quality and reduce viral infection transmission rate.

Wearing face masks and earlier lockdown exit 
An important application of this modelling is identification of a high potential of wearing face masks ir reducing exposure to airborne viruses. The reduction more than 10 times virus transmission rate via aerosol route will help to speed up the transition from the current lockdown to the normal life in many European countries. It is better to wear face masks than wear Covid-19.

\section{Conclusions}

- The results obtained demonstrate that aerosol particles from a host can travel long distances considerably more than the currently recommended $2 \mathrm{~m}$ safe distance. Aerosol particles laden with Covid-19 travel over $30 \mathrm{~m}$ and sometimes $100 \mathrm{~m}$ depending on the atmospheric conditions.

- Modelling the evolution of aerosol clouds generated by coughing and sneezing reveals that in most likely weather scenarios viruses are accumulated in the respiratory tract with the rate up to 200 virus copies in 2 min time.

- Face masks show significant reductions in the deposition dose of aerosol particles generated by sneezing or coughing from 200 virus copies down to 2 copies per $2 \mathrm{~min}$.

- The modelling also shows considerable reductions in potential infection transfer rates caused by aerosol transmission if face masks are widely used as infected, e.g. asymptomatic, as uninfected individuals.

- The modelling also suggests that aerosol particles can accumulate in public spaces such as hospitals, residential care homes and supermarkets, which could facilitate direct human-to-human aerosol transmission of Covid-19 infection.

- Covid-19 within aerosol particles in public places could be measured with suitable aerosol sampling equipment. This would give valuable insights into appropriate steps to avoid aerosol transmission of the infection by, for example, installing appropriate filter systems to remove the virus from the air.

\section{Reference}

Alisse, J.-R. and Sidi, C. (2000) Experimental probability density functions of small-scale fluctuations in the stably stratified atmosphere, J. Fluid. Mech., 402, 137-162.

Baron, P. A. and Willeke, K. (2001) Aerosol Measurement: Principles, Techniques and Applications, New York, Chichester, Weinheim, Brisbane, Singapore, Toronto: John Wiley \& Sons.

Bourouiba L, Dehandshoewoercker E, Bush J W M. (2014) Violent respiratory events: on coughing and sneezing. J Fluid Mech.;745: 537-563.

Bourouiba L. (2020) Turbulent Gas Clouds and Respiratory Pathogen Emissions Potential Implications for Reducing Transmission of COVID-19, JAMA; https://jamanetwork.com/ on 03/29/2020.

CDC Recommends Public Wear Face Masks. CDC USA (2020) https://www.cdc.gov/ 
Carvalho T.C., J.I. Peters, R.O.Williams (2011) Influence of particle size on regional lung deposition - What evidence is there? International Journal of Pharmaceutics, 406, 1-10.

Evidence summary for COVID-19 viral load over course of infection. 1 April 2020. (HIQA). Health Information and Quality Authority. Dublin, Ireland.

van Doremalen N., D. H. Morris, T. Bushmaker, M. G. Holbrook, A. Gamble, B. N. Williamson, A. Tamin, J. L. Harcourt, N. J. Thornburg, S. I. Gerber, M.D., J. O. LloydSmith, E. de Wit, V. J. Munster (2020) Aerosol and Surface Stability of SARS-CoV-2 as Compared with SARS-CoV-1, The New England Journal of Medicine, March 17. DOI: 10.1056/NEJMc2004973

Gorbunov B., R. Muir, P. Jackson, N. D. Priest (2013) Evaluation of the Airborne Particles Fraction Responsible for Adverse Health Effects, Aerosol and Air Quality Research, 13, pp. $1678-1692$.

Gorbunov B., N. Priest, P.R. Jackson and D. Cartlidge (2004) Bioavailability of lead aerosols studied with WRAS sampling kit. J. Aerosol Sci., 1, pp. S407-8.

Gorbunov B., N. D. Priest, R. B. Muir, P. R. Jackson and H. Gnewuch (2009) A Novel SizeSelective Airborne Particle Size Fractionating Instrument for Health Risk Evaluation, Ann. Occup. Hyg., v.53, pp. 225-237.

Han Z. Y., W. G. Weng and Q. Y. Huang (2013) Characterizations of particle size distribution of the droplets exhaled by sneeze. J R Soc Interface 10: 20130560; http://dx.doi.org/10.1098/rsif.2013.0560

Hanna S. R., G. A. Briggs, R. P. Hosker, Jr. (1982) Handbook on ATMOSPHERIC DIFFUSION, Ed. J.S. Smith, US Department of Energy. P. 103.

Hinds, W. C. (1999). Aerosol technology: Properties, behavior, and measurement of airborne particles. New York: Wiley.

Howard J., A. Huang, Z. Li, Z. Tufekci, V. Zdimal, H.-M. van der Westhuizen, A. von Delft, A. Price, L. Fridman, L.-H. Tang, V. Tang, G. L. Watson, C. E. Bax, R. Shaikh, F. Questier, D. Hernandez, L. F. Chu, C. M. Ramirez, and A. W. Rimoin (2020) Face Masks Against COVID-19: An Evidence Review. doi:10.20944/preprints202004.0203.v1

Hui DS, Chan PK. (2010) Severe acute respiratory syndrome and coronavirus. Infect Dis Clin North Am; 24(3):619-38. DOI: 10.1016/j.idc.2010.04.009

ICRP - International commission on radiological protection. "Human respiratory tract model for radiological protection". Annals of the ICRP, Publication 66. Tarrytown, NY: Elsevier Science Inc; 1994.

Kai-Wang Kelvin, Owen Tak-Yin Tsang, Wai-Shing Leung, Anthony Raymond Tam, TakChiu Wu, David Christopher Lung, et al. (2020). Temporal profiles of viral load in posterior oropharyngeal saliva samples and serum antibody responses during infection by SARS-CoV2: an observational cohort study. DOI:https://doi.org/10.1016/S1473-3099(20)30196-1 
Karl M., J. Kukkonen, Menno P. Keuken, S. Lützenkirchen, L. Pirjola, and T. Hussein (2016) Modeling and measurements of urban aerosol processes on the neighborhood scale in Rotterdam, Oslo and Helsinki, Atmos. Chem. Phys., 16, 4817-4835.

Kennedy, P. J. and Shapiro, M. A. (1980) Further Encounters with Clear Air Turbulence in Research Aircraft, J. Atmos. Sci., 37, 986-993.

Kodros J. K., J. Volckens, S. H. Jathar, and J. R. Pierce (2018) Ambient Particulate Matter Size Distributions Drive Regional and Global Variability in Particle Deposition in the Respiratory Tract, GeoHealth, 2, pp.298-312. https://doi.org/ 10.1029/2018GH000145

Leder K, Newman D. (2005) Respiratory infections during air travel. Intern. Med. J., 35, 50 55. (doi:10. 1111/j.1445-5994.2004.00696.x)

Leung N. H. L., D. K. W. Chu, E. Y. C. Shiu, K.-H. Chan, J. J. McDevitt, J. P. Hau, H-L. Yen, Y. Li, D. K. M. Ip, J. S. M. Peiris, W-H. Seto, G. M. Leung, D. K. Milton and B. J. Cowling (2020) Respiratory virus shedding in exhaled breath and efficacy of face masks. Nature medicine. https://doi.org/10.1038/s41591-020-0843-2

Morawska L. (2006) Droplet fate in indoor environments, or can we prevent the spread of infection? Indoor Air 16, 335 - 347. (doi:10.1111/j. 1600-0668.2006.00432.x)

Pica N, Bouvier NM (2012). Environmental Factors Affecting the Transmission of Respiratory Viruses. Curr Opin Virol. 2 (1): 90-5. doi:10.1016/j.coviro.2011.12.003. PMC 3311988. PMID 22440971.

Pruppacher, H.R. and Klett, J.D. (1997) Microphysics of Clouds and Precipitation. 2nd Edition, Kluwer Academic, Dordrecht, 954 p.

Report of the WHO-China Joint Mission on Coronavirus Disease 2019 (COVID-19) World Health Organization, (2020); https://www.who.int/docs/default- source/coronaviruse/whochina-joint-mission-on-covid-19-final-report.pdf

La Rosa, G., Frantini M., Della L. S., Iaconelli M., Muscillo M. (2013). Viral infections acquired indoors through airborne, droplet or contact transmission. Annali dell'Istituto Superiore di Sanità. 49: 124-132. doi:10.4415/ANN_13_02_03. ISSN 0021-2571.

Ruzer LS, Apte MG, Sextro RG. Aerosol dose. In: Ruzer LS, Harley NH, editors. Aerosols handbook. Measurement, Dosimetry and Health Effects (2005) p. 101e12.

Seongman Bae; Min-Chul Kim; Ji Yeun Kim; Hye-Hee Cha; Joon Seo Lim; Jiwon Jung; Min-Jae Kim, MD; Dong Kyu Oh; Mi-Kyung Lee; Seong-Ho Choi; Minki Sung; Sang-Bum Hong; Jin-Won Chung; Sung-Han Kim (2020) Effectiveness of Surgical and Cotton Masks in Blocking SARS-CoV-2: A Controlled Comparison in 4 Patients. Ann Intern Med., DOI: 10.7326/M20-1342.

Setti L., Passarini F., De Gennaro G., Barbieri P., Perrone M.G., Piazzalunga A., Borelli M., Palmisani J. (2020a), Is there a Plausible Role for Particulate Matter in the spreading of COVID-19 in Northern Italy?, BMJ Rapid Responses, April 8th 2020, available at: https://www.bmj.com/content/368/bmj.m1103/rapid-responses 
Setti L., Passarini F., De Gennaro G., Barbieri P., Perrone M.G., Borelli M., Palmisani J, Di Gilio A., Torboli V., Pallavicini A., Ruscio M., Piscitelli P., Miani A.

(2020b) SARS-Cov-2 RNA Found on Particulate Matter of Bergamo in Northern Italy: First Preliminary Evidence, https://doi.org/10.1101/2020.04.15.20065995.

Shu-An Lee, Dong-Chir Hwang, He-Yi Li, Chieh-Fu Tsai, Chun-Wan Chen, and Jen-Kun Chen (2016) Particle Size-Selective Assessment of Protection of European Standard FFP Respirators and Surgical Masks against Particles-Tested with Human Subjects, Journal of Healthcare Engineering, Article ID 8572493. http://dx.doi.org/10.1155/2016/8572493

Wilson R. (2004) Turbulent diffusivity in the free atmosphere inferred from MST radar measurements: a review. Annales Geophysicae. 22: 3869-3887.

Worldometrics (2020) Fatality Rate (case fatality ratio or CFR) of the Wuhan Coronavirus https://www.worldometers.info/coronavirus/\#repro

Xiao, J., E. Y. C. Shiu, H. Gao, J. Y. Wong, M. W. Fong, S. Ryu, and B. J. Cowling (2020) Nonpharmaceutical measures for pandemic influenza in nonhealthcare settings-personal protective and environmental measures. Emerg. Infect. Dis., 26, Number 5. https://doi.org/10.3201/eid2605.190994 (2020).

Yu IT, Qiu H, Tse LA, Wong TW. (2014) Severe acute respiratory syndrome beyond Amoy Gardens: completing the incomplete legacy. Clin Infect Dis.; 58:683-6.

YANG S, G. W. M. LEE, C.-M. CHEN, C.-C. WU, and K.-P. YU (2007) The Size and Concentration of Droplets Generated by Coughing in Human Subjects. J. of Aerosol Medicine. 20, 4, 484-494.

Zayas Gustavo, Ming C Chiang, Eric Wong, Fred MacDonald, Carlos F Lange, Ambikaipakan Senthilselvan and Malcolm King (2012) Cough aerosol in healthy participants: fundamental knowledge to optimize droplet-spread infectious respiratory disease management. BMC Pulmonary Medicine, 12:2-11.

Zhao B, Zhang Z, Li XT (2005) Numerical study of the transport of droplets or particles generated by respiratory system indoors. Build. Environ. 40, $1032-1039$.

(doi:10.1016/j.buildenv.2004.09.018) 